\title{
Electropolishing and Electrolytic Etching of Ni-Based HIP Consolidated Aerospace Forms: A Comparison between Deep Eutectic Solvents and Aqueous Electrolytes
}

\author{
Alex J. Goddard ${ }^{a}$, Robert C. Harris ${ }^{a}$, Saima Saleem ${ }^{a}$, Muhammad Azam ${ }^{a}$, \\ Christopher Hood $^{\mathrm{b}}$, Daniel Clark ${ }^{b}$, Jerry Satchwell ${ }^{b}$ and Karl S. Ryder ${ }^{*, a}$ \\ k.s.ryder@le.ac.uk \\ a Materials Centre, \\ Department of Chemistry, \\ University of Leicester, \\ Leicester, \\ LE1 7RH, UK.
}

\begin{abstract}
Here we report that the Deep Eutectic Solvent (DES), (Ethylene glycol) ${ }_{2}($ Choline chloride), $(2 \mathrm{Eg}: \mathrm{ChCl})$ is an effective medium in electrolytic removal of the Fe rich layer from Ni based Hot Isostatic Press (HIP) consolidation and that it is capable of sustaining etching at higher rates and at higher current efficiencies than a comparable aqueous electrolyte formulated from methane sulphonic acid / glycolic acid (MSA/GA). At high etch rates the surface finish is not as good using $2 \mathrm{Eg}: \mathrm{ChCl}$ but high etch rates, current efficiency and excellent surface finish can be obtained from a 90\%/10\% hybrid mixture of 2Eg: $\mathrm{ChCl} \mathrm{MSA} / \mathrm{GA}$ electrolytes. In this study we have set out to compare the electropolishing and bulk electrolytic etching of HIP formed bodies fabricated from RR1000 Ni based superalloys in aqueous methane sulphonic acid / glycolic acid (MSA/GA) electrolyte and in Deep Eutectic Solvent (DES) type ionic liquids. Samples consisting of HIP formed test coupons were electropolished under a range of conditions of current density and applied potential in either the DES (2Eg: $\mathrm{ChCl}$ ) or MSA/GA electrolytes. The samples were then characterised using a combination of methods including scanning electron microscopy (SEM), atomic force microscopy (AFM) and optical microscopy. Surface roughness and etch characteristics of the samples were determined after treatment in each of the electrolytes in order to establish the comparative efficacy of the DES. Here we present details of some of the challenges and methodologies as well as characterisation of model test pieces and forms using the scale-up facilities at the Ionic Liquids Demonstrator (ILD) facility at the University of Leicester. We show that the HIP alloy can be effectively removed under mild conditions using DES electrolytes that are of low toxicity, environmentally sustainable, relatively low cost and without the use of strong acids or chemical etchants.
\end{abstract}

Keywords: Ionic liquid, deep eutectic solvent, Ethaline 200, metal electropolishing, choline chloride, scale-up, RR 1000 superalloy, aerospace, Hot Isostatic Press (HIP). 


\section{Introduction}

Nickel based superalloys are ubiquitous in use by the modern aerospace industry for applications in many parts of civilian and military aircraft engines. A range of superalloy materials has been developed to service these demanding environments and many modern aerospace parts are fabricated from nickelbased systems (e.g. polycrystalline superalloys such as alloy 718 and waspaloy) in which there are various other minor transition element additions that have specific roles, for example, enhancing phase segregation and resulting in a lattice like metallurgical microstructure. ${ }^{1,2,3,4,5,6,7,8,9}$ The Ni based superalloys have many attractive mechanical properties including high melting temperature, high tensile strength, low coefficient of thermal expansion and low creep even at high operating temperatures. ${ }^{1}$ This combination of properties makes them ideal for operational environments that inflict high thermal and mechanical stresses despite their high cost, relatively high weight (compared to composite materials and other high strength metals such as titanium) and the demanding casting and machining technologies required to process them into engine parts. Components fabricated from these materials are most often forged or vacuum cast from the molten metal by a lost-wax investment process. The resultant rough castings are then heat treated to homogenise the microstructure and then formed into functional parts by precision grinding. The economic cost of this process is very high and it is also limited by the size and shape of the pieces that can be processed.

For shapes and forms that do not require sophisticated single crystal or uniaxial grain orientation production methods, an alternative to investment casting in the fabrication of superalloy parts is metal powder processing by Hot Isostatic Press (HIP). Here the part is formed by the high temperature sintering of the metal alloy powder under high pressure isostatic conditions. ${ }^{10,11,12}$ This process has the advantage that complex and large scale parts can be formed more quickly and more efficiently. Just as with investment casting, HIP consolidation is performed using a mould. Whereas for investment casting the mould is typically a refractory ceramic (in order to withstand the high temperatures of the molten metal) for the purposes of HIP consolidation the mould is typically formed from a thick steel can. This is possible because the temperature required for HIP consolidation (sintering) of the metal powders is well below the melting point of either the Ni based alloy or the steel can. Despite this, the mould is required to have sufficient physical integrity to maintain dimensional stability and containment at the high pressures required. To facilitate the HIP process, the steel mould is packed with the Ni-based alloy powder and then subjected to the appropriate conditions of temperature and pressure (typically by means of Ar) within a containment vessel. In subsequent processing the steel mould must then be removed.

The mould removal is simple for an investment casting process and consists of breaking off the ceramic once the casting is cooled (knock-off). However, for HIP consolidation the process is complicated by the fact that interfacial diffusion of metals at the powder/mould interfaces fuses the mould and the 
consolidated piece. Consequently, the steel mould has to be removed by selective chemical dissolution. This is achieved during post-processing by immersing the mould/consolidated form assembly in a concentrated solution of aqueous nitric acid for sufficient time to dissolve the ferrous base of the mould/can leaving the Ni-based superalloy exposed. This process is operated commercially and is quite effective but the exposed external surface of the nickel-rich compact remains rich in iron (as the primary element of the steel mould) to a depth of several hundred microns. This iron-rich diffusion layer is often detrimental to the mechanical performance of the alloy and so must be removed from the consolidated form in a separate step in order to control the metallurgical properties of the subsequent $\mathrm{Ni}$ alloy body. Typically this is achieved by a process of electrolytic anodic dissolution known as electropolishing. ${ }^{13,14,15}$

Conventional commercial electropolishing is usually performed in an aqueous electrolyte comprising a mixture of strong inorganic acids e.g. phosphoric, sulfuric or nitric acids, however, such conventional electrolytic etches often cause pitting and uneven dissolution in nickel rich substrates. Consequently electropolishing of HIP consolidated RR1000 is achieved using a commercial proprietary mixture of aqueous alkylsulphonic acid e.g. methanesulphonic acid (MSA), and glycolic acids (GA). ${ }^{16}$ This process, although functionally effective, is economically very expensive because of the high relative cost of the electrolyte (MSA/GA) and process energy. The latter is the result of low Faradaic efficiency. As a consequence, despite the technical benefits, the HIP production method is currently only applicable to either very large and/or very high value forms such as engine casings.

In contrast, we have recently developed alternative electrolytes using ionic liquids (choline chloride based deep eutectic solvents) for a range of metal finishing processes ${ }^{17,18}$ including electropolishing of stainless steels and other high performance alloys e.g. based on cobalt. ${ }^{19,20,21}$ One of the most versatile of these DES is formulated from a stoichiometric mixture of choline chloride $(\mathrm{ChCl})$ and ethylene glycol (Eg), 2Eg:ChCl. The general properties and specific applications for ionic liquid electrolytes in industrial processes and metal finishing have been described in detail recently. ${ }^{22,23,24}$ Typically ionic liquids are a good electrochemical medium offering a wide electrochemical window, high current efficiency and good solubility for metal salts. Deep eutectic solvents in particular offer relatively low cost and low environmental impact. In the context of the study presented here, $2 \mathrm{Eg}: \mathrm{ChCl}$ has a material $\operatorname{cost}(\mathrm{v} / \mathrm{v})$ that represents approximately a quarter that of the commercial aqueous MSA/GA electrolyte and has no corrosive acidic constituents. We have recently described in detail the electropolishing of stainless steels from $2 \mathrm{Eg}: \mathrm{ChCl} .{ }^{19,20}$ In this example the electrolyte is a fully functioning alternative to the commercial process but contains no phosphoric or sulphuric acids. Furthermore, we have demonstrated the efficacy of these electrolytes in the processing of Ni-based superalloy parts in the form of single crystal (SX) turbine blades. In this case we have shown that electrolytic methods utilising 
DES can be applied to remove oxide scale from SX castings as well as to remove residual surface stress prior to heat treatment. ${ }^{25}$

In this study we have aimed to explore the utility of DES as electrolytes in the electropolishing of HIP consolidated test pieces produced using Rolls-Royce powder metallurgy Ni-based alloy RR1000. Specifically to determine if $2 \mathrm{Eg}: \mathrm{ChCl}$ is effective in the polishing of RR1000 HIP consolidated samples relative to established MSA/GA electrolytes, and to quantify relative etch rates and current efficiencies of the two processes. Ultimately we are motivated by the imperative to develop sustainable, practical and economical methods of controlled removal of the external layer of HIP consolidated forms using electrolytic methods and materials that are effective and both of low toxicity and minimal impact in the work place and subsequently in the environment.

\section{Experimental}

\section{Preparation of electrolyte}

Choline chloride, $\left[\mathrm{HOC}_{2} \mathrm{H}_{4} \mathrm{~N}\left(\mathrm{CH}_{3}\right)_{3} \mathrm{Cl}\right](\mathrm{ChCl})$ (Aldrich 99\%) was recrystallised from absolute ethanol, filtered and dried under vacuum. Ethylene glycol (EG) (Aldrich 99\%), was used as received. The eutectic mixtures were formed by stirring the two constituents together, in the stated proportions, at 75 ${ }^{\circ} \mathrm{C}$ until a homogeneous, colourless liquid formed.

Methane sulphonic acid $\left[\mathrm{CH}_{3} \mathrm{OSO}_{2} \mathrm{OH}\right](\mathrm{MSA})$ and glycolic acid $\left[\mathrm{HOCH}_{2} \mathrm{COOH}\right](\mathrm{GA})$ (Aldrich $99 \%$ ) were mixed in the stoichiometric molar ratio 6:4 and diluted with distilled water such that the resultant proportion of water was $25 \% \mathrm{v} / \mathrm{v}$.

\section{Sample preparation by Hot Isostatic Press}

Test pieces were formed by Rolls-Royce in a proprietary Hot Isostatic Pressing metal powder consolidation route using a Ni-based superalloy of chemistry as for RR1000, Table 1. These materials and methods have been described previously. 1,26,27 Samples for electrochemical processing, etching and polishing of approximate dimensions approx. $20 \times 30 \mathrm{~mm}$ were cut from these pieces using wire electrical discharge machining (EDM).

\section{Surface characterisation}

Surface analysis was carried out using; Digital Instruments Nanoscope IV Dimension 3100 (Veeco) atomic force microscope with a $100 \mu \mathrm{m}$ scanning head and run using and tapping (resonant) modes; Alicona InfiniteFocus 3G optical profiling microscope and a Zeta-20 3D Imaging \& Metrology System. A Phillips XL-30 Field Emission Gun scanning electron microscopy (FEG SEM) was used equipped with a Bruker AXS XFlash 4010 EDS detector operating at $25 \mathrm{kV}$. Secondary electron imaging (SEI) was performed with a typical working distance of $c a .11 \mathrm{~mm}$ and accelerating voltage of $c a .15 \mathrm{kV}$. 


\section{Electropolishing}

Electropolishing of RR1000 HIP alloys was carried out by immersion in either 2Eg: $\mathrm{ChCl}$ or aqueous MSA/GSA electrolytes using a purpose built $70 \mathrm{~L} \mathrm{scale}$ pilot plant situated at the Ionic Liquids Demonstrator (ILD) facility at the University of Leicester. ${ }^{21}$ A low-ripple rectifier (32 A, 24 V) was used under controlled potential conditions with iridium oxide coated platinised Ti mesh cathodes. On a smaller scale galvanostatic and potentiostatic electropolishing and dissolution experiments were carried out using Micro Autolab (III) potentiostats with GPES v9 software. A two electrode cell was used with a platinised iridium oxide coated Ti mesh as the cathode and the sample material (HIP, RR1000) as the anode.

\section{Results \& Discussion}

\section{Methodology}

In electrolytic dissolution (polishing/etching) the metal removal rates i.e. etch depth and surface finish (roughness) achieved during electropolishing are a function of liquid formulation (metal ion solubility), temperature and electrochemical regime, e.g. applied potential and current density. In this context we have sought to determine etch rates and surface finish using a combination of surface profiling techniques including scanning electron microscopy, atomic force microscopy (AFM) and 3D optical profilometry (3DM). Whilst AFM provides a strong insight into the native substrate structure as well as high resolution (nm) quantitative information in respect of surface finish, it is limited in the extent of surface that can be traversed (in the plane of the substrate) in a single image (typically 100x100 $\mu \mathrm{m}$ ) and by a relatively low tolerance of absolute roughness $(c a .5 \mu \mathrm{m})$. In contrast 3DM is capable of imaging much larger areas of the surface and much rougher surfaces in a much shorter time scale but at a lateral resolution limited by visible light. Using these complimentary methods, AFM, 3DM and SEM we have recently been able to study phase selectivity in the electropolishing of single crystal Nibased alloys at the sub $\mu \mathrm{m}$ scale (AFM) as well as bulk etch profiling at the sub mm scale (3DM). ${ }^{28}$

In the experiments reported here we have set out to compare the electrolytic polishing/etching of test coupons cut from HIP consolidated forms using RR1000 alloy in both conventional MSA/GA electrolytes and DES type ionic liquids. Initially we have formulated lab. scale volumes of the DES ionic liquid electrolyte 2Eg: $\mathrm{ChCl}$, subsequently samples consisting of HIP formed test coupons were electropolished under a range of conditions of either constant current or constant applied potential in either 2Eg: $\mathrm{ChCl}$ or $\mathrm{MSA} / \mathrm{GA}$ electrolytes. The range of samples and experimental conditions is summarised in Table 2. The samples were then characterised using a combination of methods including scanning electron microscopy (SEM), atomic force microscopy (AFM) and optical microscopy, as 
appropriate. Surface roughness and etch characteristics of the samples were determined for samples treated with each of the electrolytes in order to establish efficacy of the DES medium.

To determine etch depths resulting from electropolishing of RR1000 HIP consolidated samples 3D optical profiling was performed using a Zeta 20 3D imaging and metrology system. Here a region of cut sample token was masked with acrylic polymer resin and the sample was electropolished for periods of time at a fixed value of either applied potential or driven current. The sample was then removed from the polishing tank, rinsed and the mask resin dissolved using acetone. The sample was then imaged in the polished and unpolished regions across the mask edge boundary.

\section{Electropolishing in 2Eg: $\mathrm{ChCl}$}

The DES 2Eg: $\mathrm{ChCl}$ is a 1:2 mixture of an organic salt, choline chloride, and ethylene glycol, Figure 1. The trials commenced by electropolishing a single token in $2 \mathrm{Eg}: \mathrm{ChCl}$ for a period of 30 minutes at an applied potential of $6 \mathrm{~V}$ in a two electrode cell with a Ti/Ir oxide mesh cathode. The sample was partially masked (as above), using acrylic resin, in order to provide topographical/compositional contrast between exposed (electropolished) and unexposed areas. A photograph of this sample (labelled S-13V, Table 2) is presented in Figure 1 and SEM images of the corresponding polished and unpolished regions are shown in Figure 2. Here it can be seen clearly that the electropolished surface is optically smoother than the untreated region and that a discernible amount of metal has been removed during electropolishing. Interestingly, the particulate grain morphology intrinsic to the bulk of the HIP consolidated material is revealed in the electropolished surface, Figure 2(b). This is evidence that the outer most interface of the piece has been removed.

The nominal bulk atomic composition of RR1000 powder used in this study is given in Table 1. ${ }^{29}$ Elemental analysis was performed on the sample (S-13V) by EDX in the SEM in both polished and unpolished regions and the data are presented in Figure 3. Most importantly these data show that in the electropolished region the $\mathrm{Fe}$ content of the surface is $c a$. $7 \%$ compared to $20 \%$ for the untreated surface. The higher Fe content of the unpolished surface is evidence of the diffusion zone from the steel mould. The data presented in Figure 3 also show a consequential increase in Ni content from $40 \%$ at the unpolished surface to $47 \%$ at the polished surface. This is consistent with removal of the Fe rich diffuse layer. However, these data show that for the treated surface $i$ ) there are still high levels of residual $\mathrm{Fe}$ and that $\mathrm{ii}$ ) the measured proportion of $\mathrm{Ni}$ in the polished region, $47 \%$, is still below that representative of the bulk composition, $c a .52 \%$, Table 1. Consequently, it is clear that under these conditions not all of the diffuse layer had been removed.

The 3D surface morphology of the polished region of sample S-13V was also examined using tapping mode atomic force microscopy (AFM), Figure 4. This showed a surface condition consistent with the SEM, Figure 2(b), with undulations (indents) corresponding to coalesced powder particles from the 
HIP consolidation. A single line-trace from the image shown in Figure 4(a) is presented in Figure 4(b). This shows a peak to trough amplitude surface roughness of around $250 \mathrm{~nm}$ over the $40 \mu \mathrm{m}$ length of the line scan. The unpolished surface is too rough (i.e. roughness $>10 \mu \mathrm{m}$ ) to be characterised using AFM in this way.

Furthermore, surface profiling over a wider sample area was achieved using a white light focus variation microscope (3DM). This gave good resolution of surface detail and good metrology. A representative data set is shown for sample S-13V in Figure 5. Here the step height over a line trace ( $450 \mu \mathrm{m})$ is over $18 \mu \mathrm{m}$, Figure 5(a). The focus variation method also gives a very good 3D representative view of the boundary between electropolished and unpolished regions, Figure 5(b). Once again here the rough amorphous untreated surface is visible in contrast with the exposed, smoother consolidated material.

In another experiment a HIP token sample was polished under the same conditions over a period of 60 minutes but with sequential withdrawal from the electrolytes at periods of 10 minutes. This gave a stepped polish in which the surface finish was examined at each 10 minute interval. The optical image and representative SEM images are shown in Figure 6. These data show sequential removal of the external surface and a graded improvement in surface finish with increasing polishing time. (Individual step edges were not measured because the magnitude of the step height is relatively small with respect to the overall surface roughness). The surface roughness, $R_{a}$ (measured along a $100 \mu \mathrm{m}$ line scan, averaged over five measurements, from the Zeta optical profilometer), after 10 mins electropolish was measured at $894 \mathrm{~nm}$, after 30 mins this was reduced to $773 \mathrm{~nm}$ and after a total of 60 mins. the final value of surface roughness was $645 \mathrm{~nm}$.

From these data we conclude that $2 \mathrm{Eg}: \mathrm{ChCl}$ is an effective medium for the electrolytic removal of the alloy and in improving the surface finish.

\section{Comparative etching}

A series of samples were etched in either MSA/GA or $2 \mathrm{Eg}: \mathrm{ChCl}$ electrolyte over a range of constant current (chronopotentiometric) or constant applied potential (chronoamperrometric) conditions, Table 2. Temperature was controlled at between $40-50{ }^{\circ} \mathrm{C}$ for all etching experiments. In chronoamperrometric experiments (samples labelled $\mathrm{S}-x \mathrm{~V}, x=$ number) the applied potential was controlled between 4-10 V. A lower limit of $4 \mathrm{~V}$ was required for initiation of metal dissolution whilst at anodic potentials in excess of $10 \mathrm{~V}$ we have observed rapid degradation of the DES electrolyte and also very low current efficiencies (particularly in aqueous media). In chronopotentiometric etching experiments (samples labelled S- $x \mathrm{C}, x=$ number) the current density was adjusted for sample area and controlled at $70 \mathrm{~mA} \mathrm{~cm}^{-2}$. This value of current density was chosen in order to keep the applied potential in the range 4-10 V during the course of the experiment. The time scale of etching was also varied between 10 minutes and 120 minutes. A range of results were obtained and some of the samples were 
photographed and presented here as Figure 7(a). A wide range of surface finishes was obtained from both electrolytes; qualitatively the best and most consistent/homogeneous surface finishes were obtained using constant applied potential methods.

Current efficiency: In several of these experiments the mass loss of the sample was measured along with the total Faradic charge passed and subsequently expressed as a mass/charge ratio, Table 2, which is related to the current efficiency. These data are also presented graphically in Figure 8. For these alloys the quantitative current efficiency for electrolytic dissolution is not easily determined because of the complex mix of metals and redox processes. However, the RR1000 alloy comprises $c a .52 \% \mathrm{Ni}$ and the bulk of the remainder consists of metals, Co and Cr (Table1). Assuming that under these conditions the final oxidation states of these dissolved metals ions is $\mathrm{Ni}^{2+}, \mathrm{Co}^{2+}$ and $\mathrm{Cr}^{3+}$ then the Faradaic dissolution ratio for the alloy can be estimated at $2.7 \times 10^{-4} \mathrm{~g} \mathrm{C}^{-1}$ for a current efficiency of 100\%. Thus it can be estimated from Table 2 that the samples treated under constant current conditions in aqueous MSA/GA electrolyte, S-9C and S-10C, gave approximate current efficiencies of 33\% and $28 \%$ respectively. A sample treated in aqueous MSA/GA under constant voltage conditions, S-9V (applied potential of $6 \mathrm{~V}$ ), gave a similar current efficiency of 35\%. These variations are probably within the margin of experimental error and the low values are not surprising given the nature of the aqueous acid electrolyte. On the other hand, samples treated in neat 2Eg: $\mathrm{ChCl}, \mathrm{S}-10 \mathrm{~V}$ (120 mins.) and S-13V (30 mins.), under potential control (applied potential of $6 \mathrm{~V}$ ) gave much higher current efficiencies of 56\% and 59\% respectively. This seemed largely independent of etching time. A sample treated in neat 2Eg:ChCl, for 120 mins. at an increased applied potential of $10 \mathrm{~V}, \mathrm{~S}-11 \mathrm{~V}$, gave a lower current efficiency of $43 \%$. Here current efficiency is diminished because the applied potential is at the limit of the electrochemical operational window of the DES. Consequently, it is clear from these observations that the current efficiency of electrolytic dissolution is much higher in $2 \mathrm{Eg}: \mathrm{ChCl}$ than in the aqueous MSA/GA electrolyte.

Surface finish: In addition, we have studied the influence of electrolyte on the metal removal rate and the condition of the treated surface. For the sample etched in MSA/GA for 120 min. at $6 \mathrm{~V}$ (S9V), Figure 7(b), SEM images showing the surface morphology of polished and unpolished regions as well as SEM profile images of the step edge at the boundary are presented are presented in Figure 9. These show an even and isotropic etch over the measured area with a step height of $111 \mu \mathrm{m}$ between the treated and untreated regions. Similar images were recorded for the sample etched in 2Eg:ChCl, S-10V. Both optical and SEM imaging show similar features in both etched samples with effective removal of metal in both cases. Furthermore, the wider electrochemical window of the DES enables operation at more anodic potentials; the SEM data for the sample etched in $2 \mathrm{Eg}: \mathrm{ChCl}$ at $10 \mathrm{~V}, \mathrm{~S}-11 \mathrm{~V}$, are shown in Figure 10. Again the etch is even and isotropic over the imaged area with a step edge of $300 \mu \mathrm{m}$ between the treated and untreated regions. Hence under these conditions much more metal is 
removed in the same time. However, close examination of the latter sample, Figure 7(c), shows regions of macroscopic pitting and unevenness. This is evidence that greatly increased metal removal rates are possible with 2Eg: $\mathrm{ChCl}$, but that this is at a cost of increased surface roughness and poorer finish.

In order to obtain a good finish offered by the MSA/GA electrolyte but also the high current densities (rapid metal removal rates) made possible in $2 \mathrm{Eg}: \mathrm{ChCl}$ a third experiment was performed in which a hybrid electrolyte was used. This comprised 90\% 2Eg: $\mathrm{ChCl}$ mixed with 10\% MSA/GA v/v. A sample etched in this hybrid electrolyte (S-12V) is shown in Figure 7(d) with corresponding SEM images in Figure 11, showing a step edge of $260 \mu \mathrm{m}$ between the treated and untreated regions. In this case good metal removal rates were obtained and a very good surface finish was achieved.

In addition to the improvement in surface finish and metal removal rates offered by the hybrid electrolyte we also observe significant variations in the estimated current efficiency. The sample treated at constant current (S-8C) gave a current efficiency of 50\% (compared with $33 \%$ for S-9C and $28 \%$ S10C), whereas the sample etched at constant applied potential of $10 \mathrm{~V}(\mathrm{~S}-12 \mathrm{~V})$ gave the highest current efficiency observed at $73 \%$. Rather surprisingly we also see that in a similar experiment where the sample is treated in hybrid electrolyte at a less anodic potential of $6 \mathrm{~V}(\mathrm{~S}-8 \mathrm{~V})$ the estimated current efficiency is the lowest measured at $27 \%$. The reason for this effect is not clear but it could be the result of a reduced water activity in the diffusion layer caused by the higher dissolution rate. In general DES are quite tolerant of water content but increasing water concentration does result in a consequential decrease in current efficiency. In this case the more anodic potential will drive the dissolution reaction much faster and hence saturate the diffusion layer of the electrolyte with dissolved metal ions. These metal ions will probably coordinate water solute and hence reduce the free-water content of the electrolyte layer adjacent to the metal surface.

Nevertheless, these observations show that the sample etched in the hybrid electrolyte (S-12V) shows the greatest metal removal per unit charge and consequently the hybrid electrolyte is the most current efficient in addition to providing an excellent surface finish that is comparable to both the commercial MSA/GA electrolyte or the DES at low potential.

Compositional data: Elemental composition data were acquired using EDX in the SEM for all samples shown in Table 2 and the Fe and Ni components are presented as a function of electropolishing etch depth, measured using optical profilommetry, in Figure 12. These clearly show that $\mathrm{Fe}$ concentration drops rapidly with etch depth and as a consequence Ni concentration in the HIP consolidated alloy rises. From these data, the thickness of the diffuse layer (in these samples) is estimated at between 200-400 $\mu \mathrm{m}$. Removal of this quantity of metal from the surface is demonstrably possible and easily achievable using either MSA/GA, pure 2Eg: $\mathrm{ChCl}$ or with the hybrid. 


\section{Conclusions}

Here we have described a new methodology for the removal of the iron rich diffusion layer in HIP consolidated forms fabricated using powder metallurgy methods with Ni-based superalloy RR1000 using 2Eg: $\mathrm{ChCl}$, a novel choline chloride based deep eutectic solvent. We have set out to compare the electropolishing and bulk electrolytic etching of HIP consolidated test pieces fabricated from RR1000 Ni-based superalloys in aqueous methane sulphonic acid / glycolic acid (MSA/GA) electrolyte and in Deep Eutectic Solvent (DES) type ionic liquids. Samples consisting of HIP formed test coupons were electropolished under a range of conditions of current density and applied potential in either the DES known as $2 \mathrm{Eg}: \mathrm{ChCl}$ or $\mathrm{MSA} / \mathrm{GA}$ electrolytes. We conclude here that the $\mathrm{DES}, 2 \mathrm{Eg}: \mathrm{ChCl}$, is an effective medium for electrolytic removal of the Fe rich layer from Ni based HIP consolidations and that it is capable of sustaining etching at higher rates and higher current efficiencies than a comparable aqueous electrolyte formulated from methane sulphonic acid / glycolic acid (MSA/GA). At high etch rates the surface finish is not as good using $2 \mathrm{Eg}: \mathrm{ChCl}$, samples exhibiting higher surface roughness than under equivalent conditions using aqueous MSA/GA, but high etch rates, current efficiency and excellent surface finish can be obtained from a 90\%/10\% hybrid mixture of $2 \mathrm{Eg}: \mathrm{ChCl}$ and MSA/GA electrolytes. In summary, we have shown that the HIP alloy can be effectively removed under mild conditions using liquids that are of low toxicity, environmentally sustainable, relatively low cost and without the use of strong acids or chemical etchants.

\section{Acknowledgements}

KSR would like to thank the Royal Society for funding under the Industry Fellowship Scheme (IF090090) and the Technology Strategy Board for funding under the Sustainable Manufacturing for the Process Industry call (project SUPERALLOY, Ref. 101327). 


\begin{tabular}{lccccccccccc}
\hline Element & Cr & Co & Al & Mo & Ti & Ta & Zr & C & B & Hf & Ni \\
\hline Wt.\% & 15 & 18.5 & 3 & 5 & 3.6 & 2 & 0.06 & 0.027 & 0.015 & 0.5 & Bal. \\
At.\% & 16.5 & 17.9 & 6.4 & 30 & 4.3 & 0.6 & 0.04 & 0.13 & 0.08 & 0.16 & Bal. \\
\hline
\end{tabular}

Table 1: Nominal elemental composition of the powder metallurgy Ni-based superalloy RR1000 (from ref. 29). 


\begin{tabular}{|c|c|c|c|c|c|c|}
\hline Sample & Electrolyte & $\begin{array}{l}\text { Time } \\
t / \min .\end{array}$ & $\begin{array}{c}\text { Constant } \\
\text { current } \\
i / \mathrm{mA} \mathrm{cm}^{-2}\end{array}$ & $\begin{array}{c}\text { Constant } \\
\text { voltage } \\
E / \mathrm{V}\end{array}$ & $\begin{array}{l}\text { Faradaic } \\
\text { mass loss } \\
/ 10^{-4} \mathrm{~g} \mathrm{C}^{-1}\end{array}$ & $\begin{array}{l}\text { Temp. } \\
T /{ }^{\circ} \mathrm{C}\end{array}$ \\
\hline S-1C & 2Eg: $\mathrm{ChCl}$ & 30 & 70 & - & - & 40 \\
\hline $\mathrm{S}-2 \mathrm{C}$ & 2Eg: $\mathrm{ChCl}$ & 30 & 70 & - & - & 50 \\
\hline $\mathrm{S}-3 \mathrm{C}$ & MSA:GA & 30 & 70 & - & - & 40 \\
\hline S-4C & $\begin{array}{c}2 \mathrm{Eg}: \mathrm{ChCl} / \mathrm{MSA}: \mathrm{GA} \\
(90: 10) \% \mathrm{v} / \mathrm{v}\end{array}$ & 30 & 70 & - & - & 40 \\
\hline S-5C & $\begin{array}{c}2 \mathrm{Eg}: \mathrm{ChCl} / \mathrm{MSA}: \mathrm{GA} \\
(90: 10) \% \mathrm{v} / \mathrm{v}\end{array}$ & 60 & 70 & - & - & 40 \\
\hline$S-6 C$ & $\begin{array}{c}\text { 2Eg:ChCl / GA (90:10) } \\
\% \mathrm{v} / \mathrm{v}\end{array}$ & 30 & 70 & - & - & 40 \\
\hline S-7C & $\begin{array}{c}2 \mathrm{Eg}: \mathrm{ChCl} / \mathrm{MSA}(90: 10) \\
\% \mathrm{v} / \mathrm{v}\end{array}$ & 30 & 70 & - & - & 40 \\
\hline S-8C & $\begin{array}{c}\text { 2Eg: } \mathrm{ChCl} / \mathrm{MSA}: \mathrm{GA} \\
(90: 10) \% \mathrm{v} / \mathrm{v}\end{array}$ & 120 & 70 & - & 1.36 & 40 \\
\hline S-9C & MSA:GA & 120 & 70 & - & 0.88 & 40 \\
\hline S-10C & MSA:GA & 120 & 70 & - & 0.75 & 40 \\
\hline S-1V & 2Eg: $\mathrm{ChCl}$ & 10 & - & 6.0 & & 40 \\
\hline $\mathrm{S}-2 \mathrm{~V}$ & $2 E g: C h C l$ & 30 & & 6.0 & & 40 \\
\hline$S-3 V$ & MSA:GA & 10 & & 6.0 & & 40 \\
\hline $\mathrm{S}-4 \mathrm{~V}$ & MSA:GA & 30 & & 6.0 & & 40 \\
\hline $\mathrm{S}-5 \mathrm{~V}$ & $2 \mathrm{Eg}: \mathrm{ChCl}$ & 10 & & 6.0 & & 50 \\
\hline$S-6 V$ & 2Eg:ChCl & 30 & & 6.0 & & \\
\hline $\mathrm{S}-7 \mathrm{~V}$ & 2Eg: $\mathrm{ChCl}$ & 60 & & 6.0 & & 40 \\
\hline S-8V & $\begin{array}{c}\text { 2Eg: } \mathrm{ChCl} / \mathrm{MSA}: \mathrm{GA} \\
(90: 10) \% \mathrm{v} / \mathrm{v}\end{array}$ & 120 & - & 6.0 & 0.72 & 40 \\
\hline S-9V & MSA:GA & 120 & - & 6.0 & 0.94 & 40 \\
\hline S-10V & 2Eg: $\mathrm{ChCl}$ & 120 & - & 6.0 & 1.57 & 40 \\
\hline S-11V & $2 \mathrm{Eg}: \mathrm{ChCl}$ & 120 & - & 10.0 & 1.17 & 40 \\
\hline S-12V & $\begin{array}{c}2 \mathrm{Eg}: \mathrm{ChCl} / \mathrm{MSA}: \mathrm{GA} \\
(90: 10) \% \mathrm{v} / \mathrm{v}\end{array}$ & 120 & - & 10.0 & 1.96 & 40 \\
\hline S-13V & 2Eg:ChCl & 30 & - & 6.0 & 1.52 & 50 \\
\hline
\end{tabular}

Table 2: Experimental conditions for the electrolytic etching of HIP consolidated samples. The sample designation $\mathrm{S}-x \mathrm{~V}$, or $\mathrm{S}-x \mathrm{C}$ refer to constant voltage or constant current conditions respectively. 


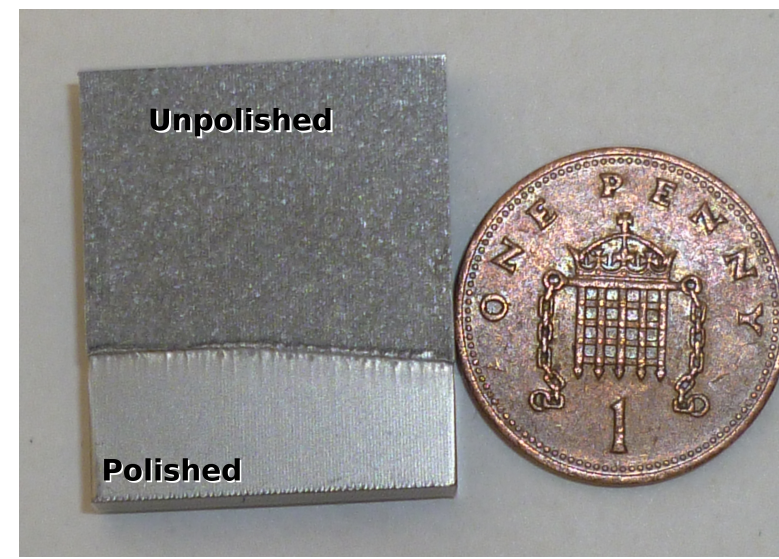<smiles>C[N+](C)(C)CCO</smiles>

Choline Chloride

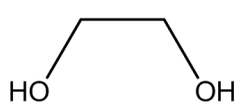

Ethylene Glycol

Figure 1:

Sample of HIP consolidated token (left, sample S-13V) partially masked and then electropolished in 2Eg: $\mathrm{ChCl}$ at $6 \mathrm{~V}$ for 30 minutes. The labels indicate the unpolished (masked) and polished areas of the sample. Structural representations of the constituents of $2 \mathrm{Eg}: \mathrm{ChCl}$ (right).

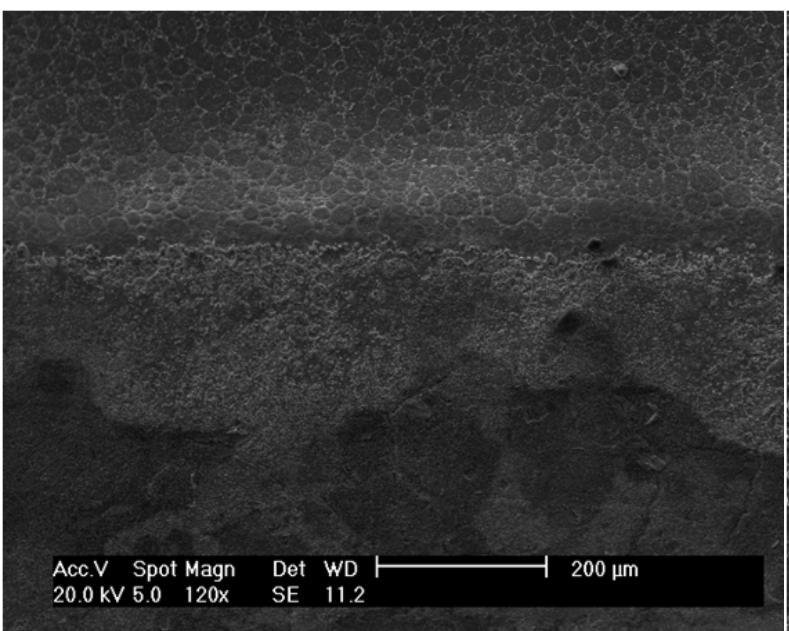

(a)

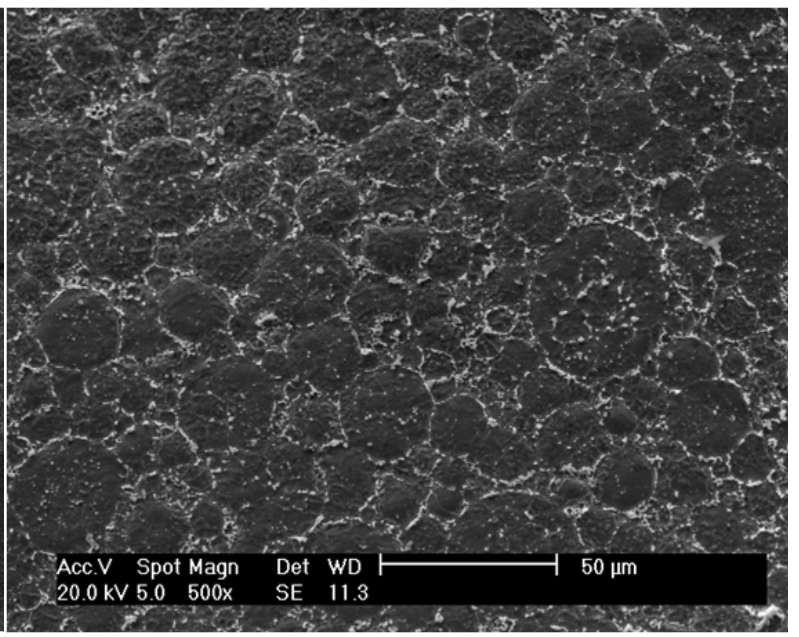

(b)

Figure 2: $\quad$ SEM images of the piece shown in Fig. 1; (a) the boundary region between polished (above) and unpolished (below) regions; (b) the electropolished region at higher magnification. 


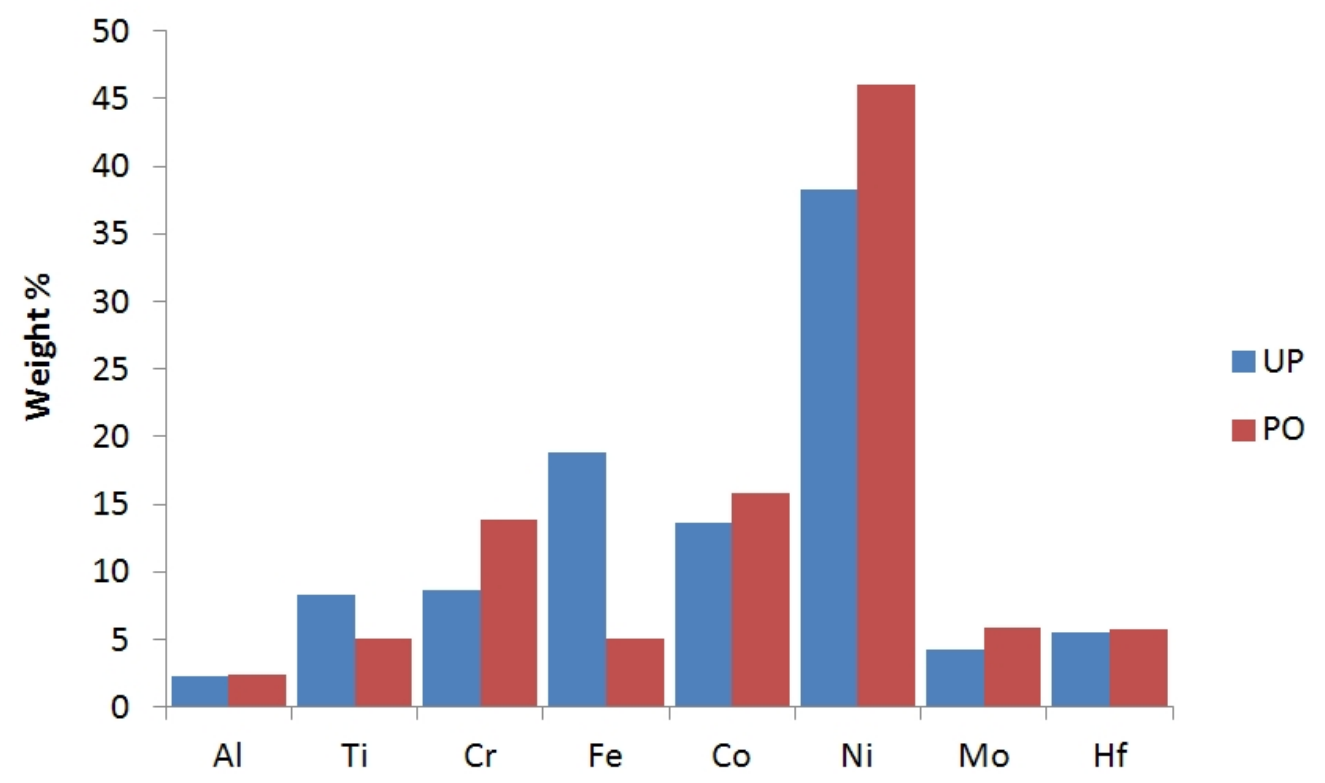

Figure 3:

EDX analysis of polished (PO) and unpolished (UP) regions of the HIP consolidated section electropolished in 2Eg: $\mathrm{ChCl}$, shown in Fig. 1. 


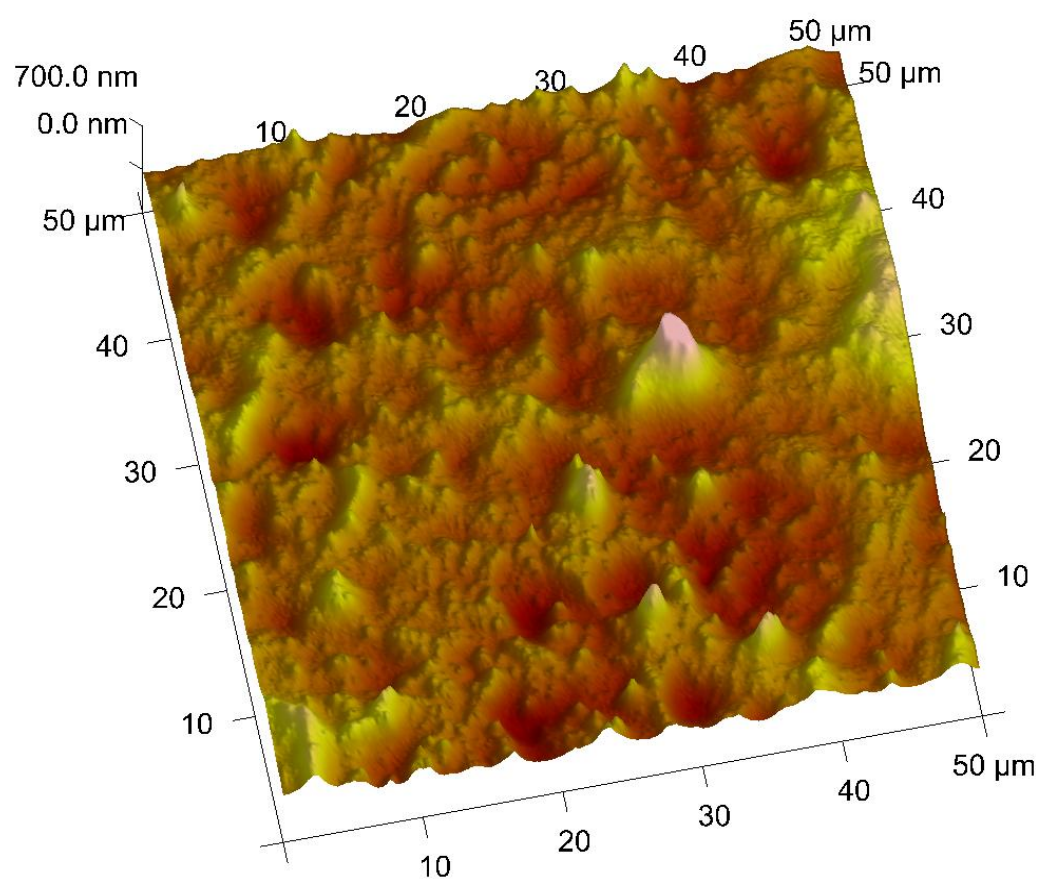

(a)

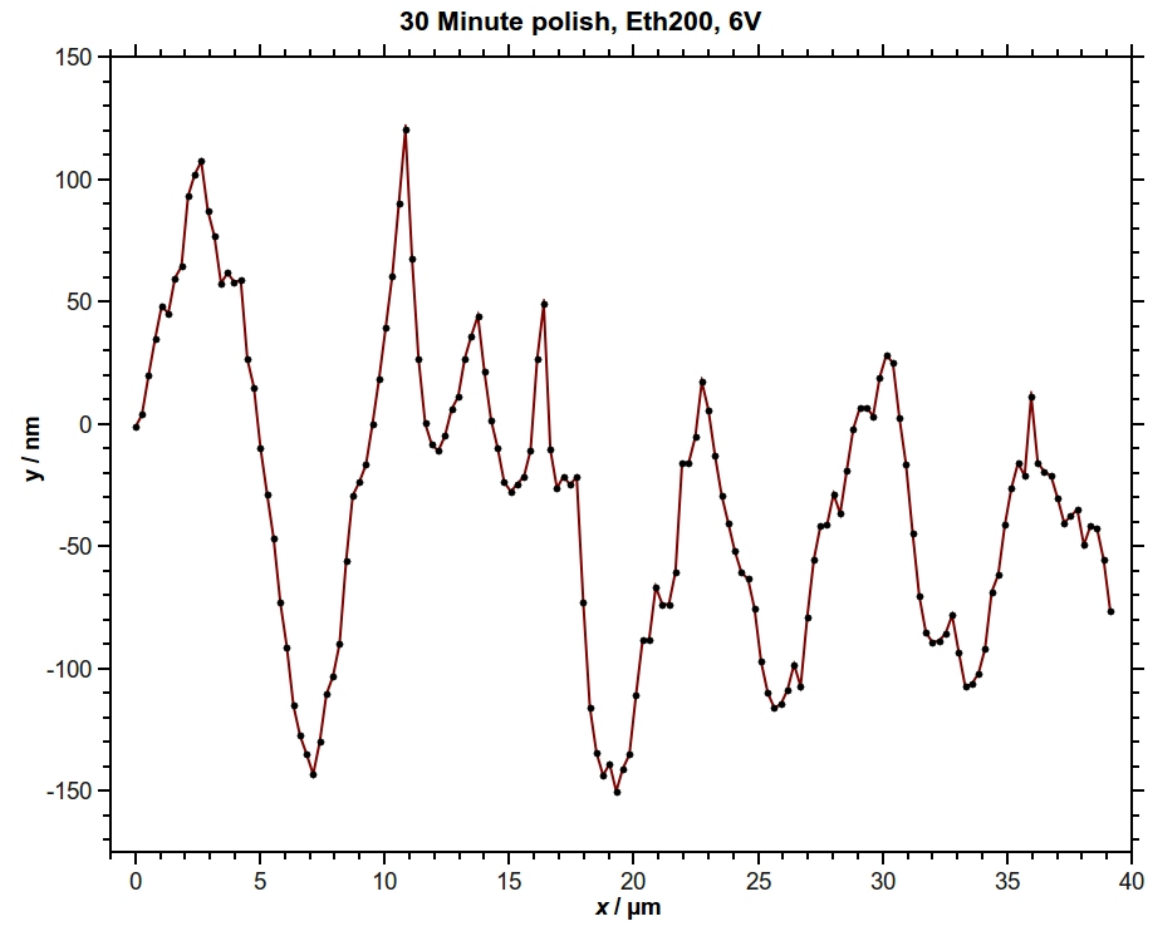

(b)

Figure 4:

AFM image, (a), of polished region from the sample shown in Fig. 1; associated roughness shown in the horizontal line trace, (b), taken on the same region of the surface. 


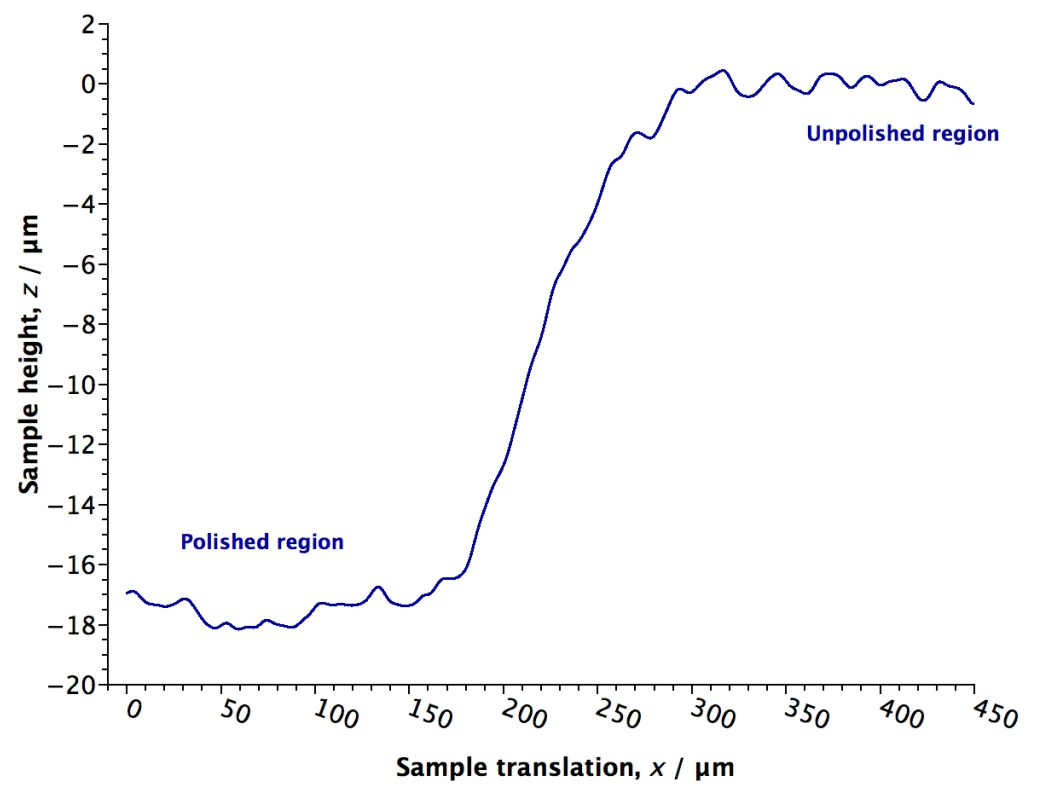

(a)

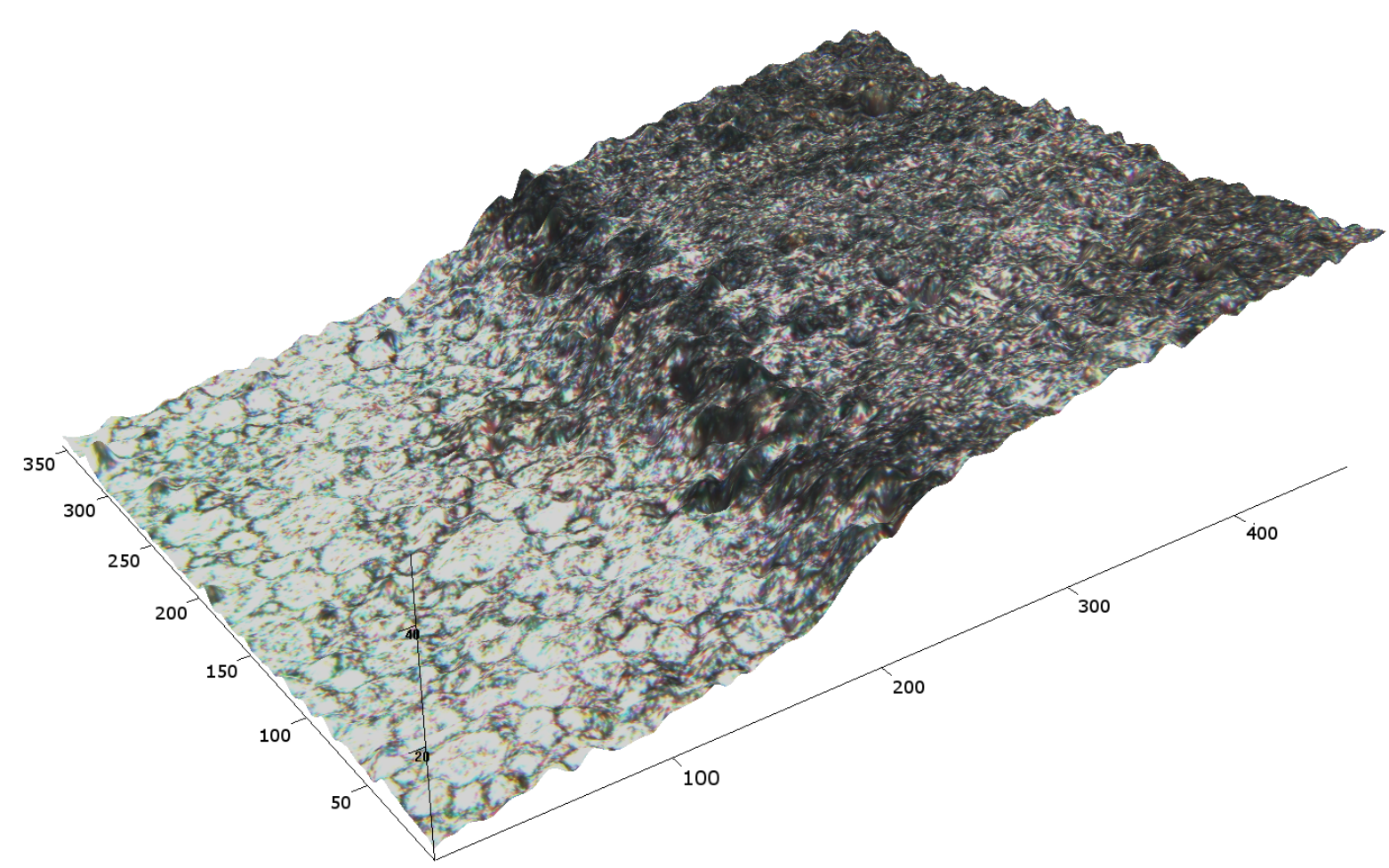

(b)

Figure 5:

Optical profilometry of sample S-13V (Fig. 1) electropolished for 30 minutes at $6 \mathrm{~V}$ in 2Eg:ChCl; (a) measured section and profile of step edge; (b) 3D representation of surface across the boundary region between polished and unpolished surfaces. 


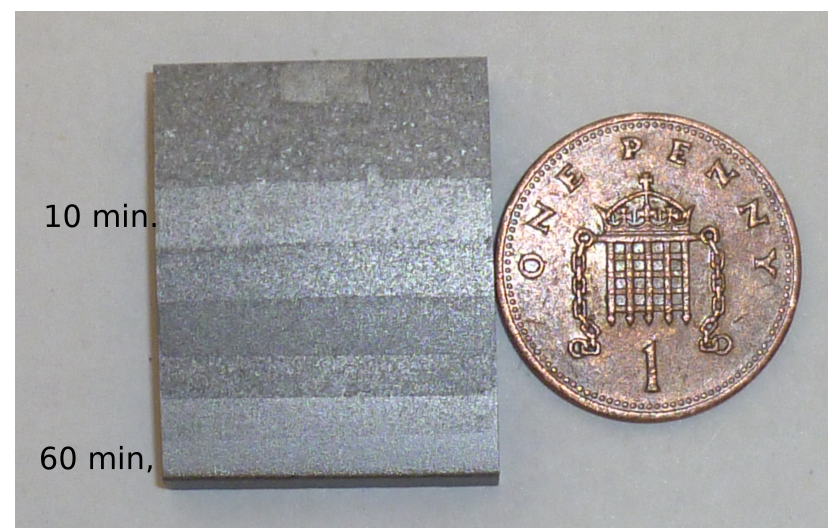

(a)

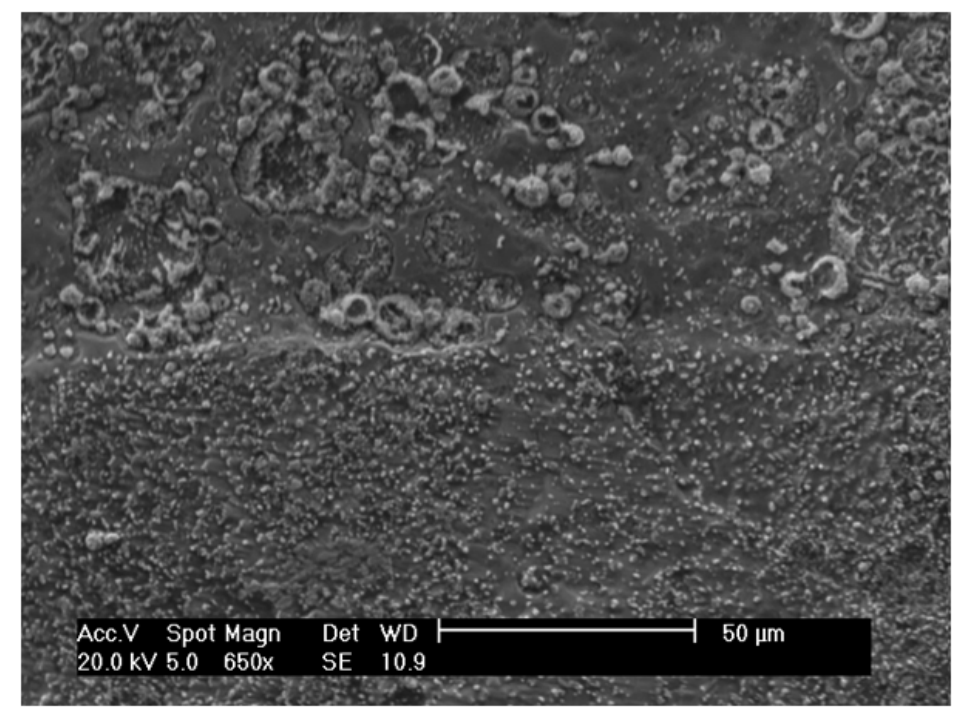

(b)

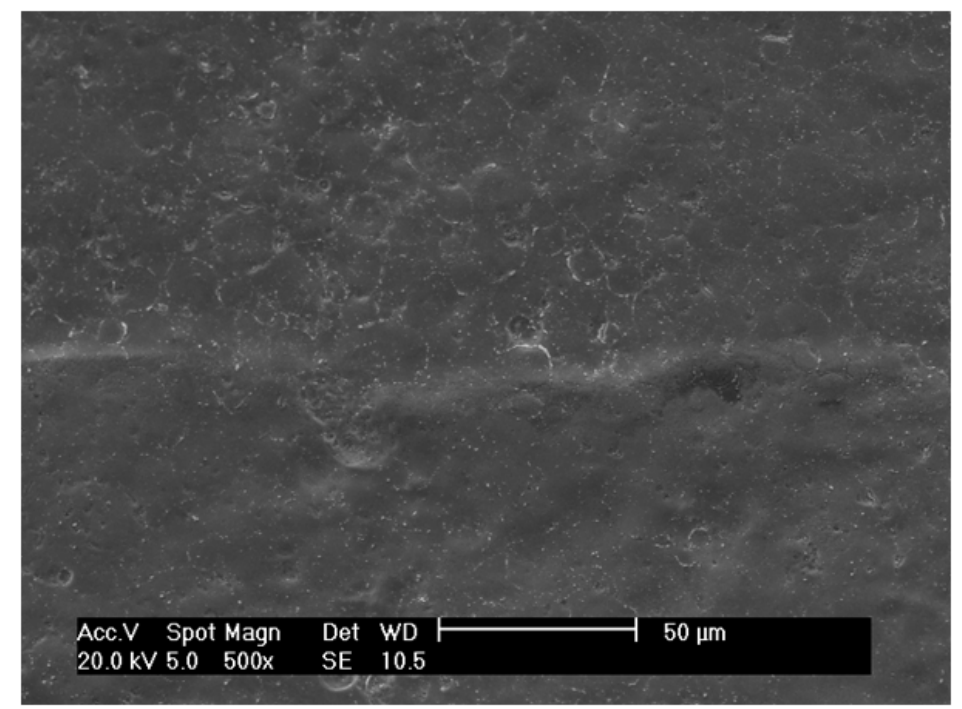

(c)

Figure 6: $\quad$ HIP consolidated token electropolished in $2 \mathrm{Eg}: \mathrm{ChCl}$ at $+6 \mathrm{~V}$ by sequential withdrawal for periods of 10, 20, 30, 40, 50 and 60 minutes; (a) sample photograph after experiment; (b) SEM image of the interface between unpolished region (top) and region polished for 10 minutes (bottom); (c) SEM image of the interface between region polished for 50 minutes (top) and region polished for 60 minutes (bottom). 


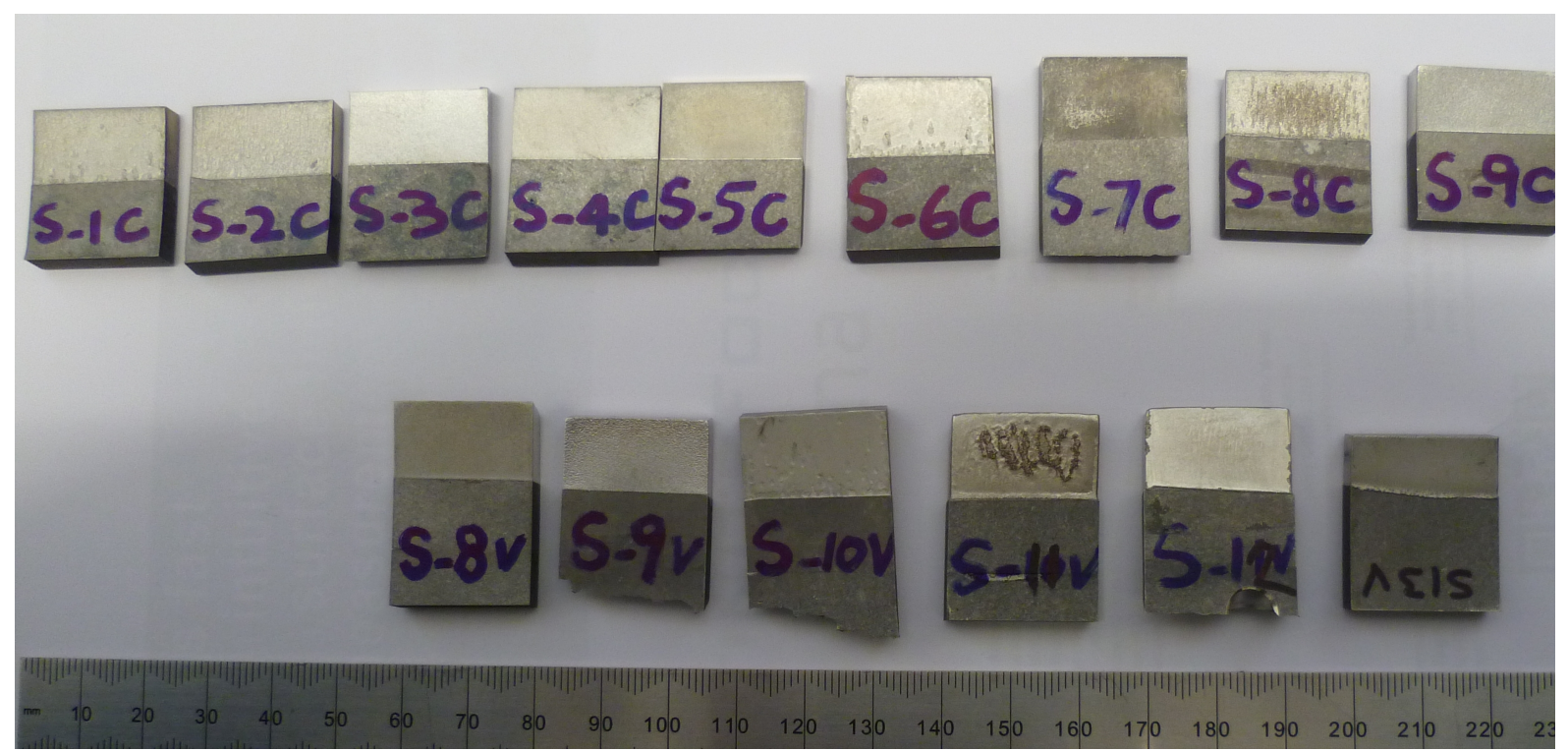

(a)

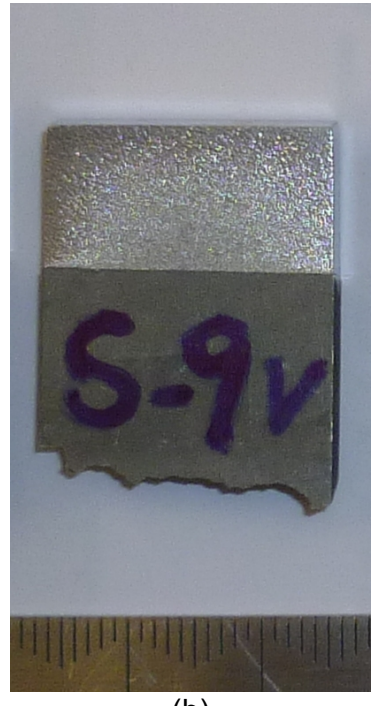

(b)

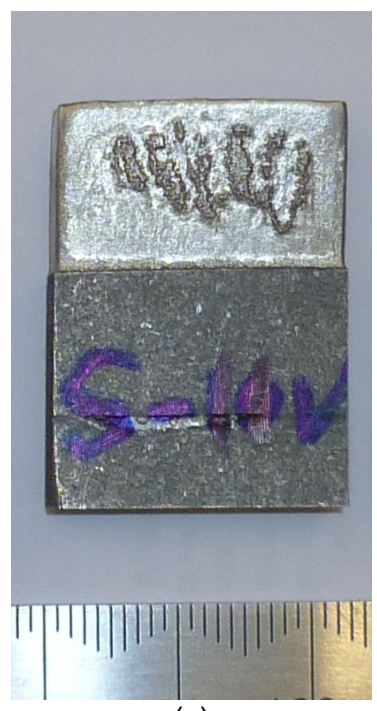

(c)

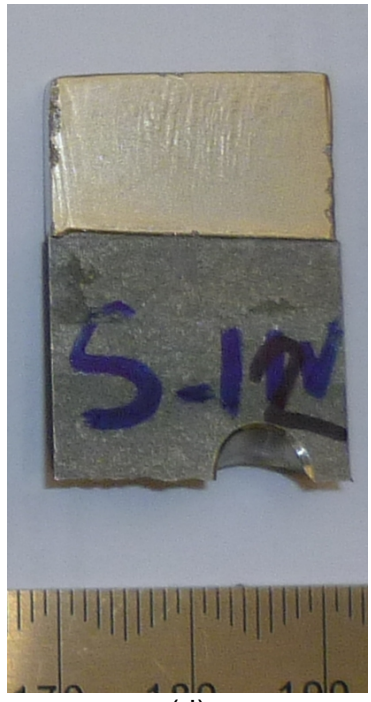

(d)

Figure 7:

HIP consolidated samples electropolished in 2Eg: $\mathrm{ChCl}$, or MSA/GA; (a) constant current $(\mathrm{S}-x \mathrm{C})$ and constant voltage $(\mathrm{S}-x \mathrm{~V})$ conditions;

over a range of electropolished for 120 minutes at $6 \mathrm{~V}$ in MSA/GA; (c) sample S-11V electropolished for 120 minutes at $10 \mathrm{~V}$ in $2 \mathrm{Eg}: \mathrm{ChCl}$; (d) sample S-12V electropolished for 120 minutes at 10 $\mathrm{V}$ in mixed electrolyte [ $90 \% 2 \mathrm{Eg}: \mathrm{ChCl}: 10 \% \mathrm{MSA} / \mathrm{GA}]$. 


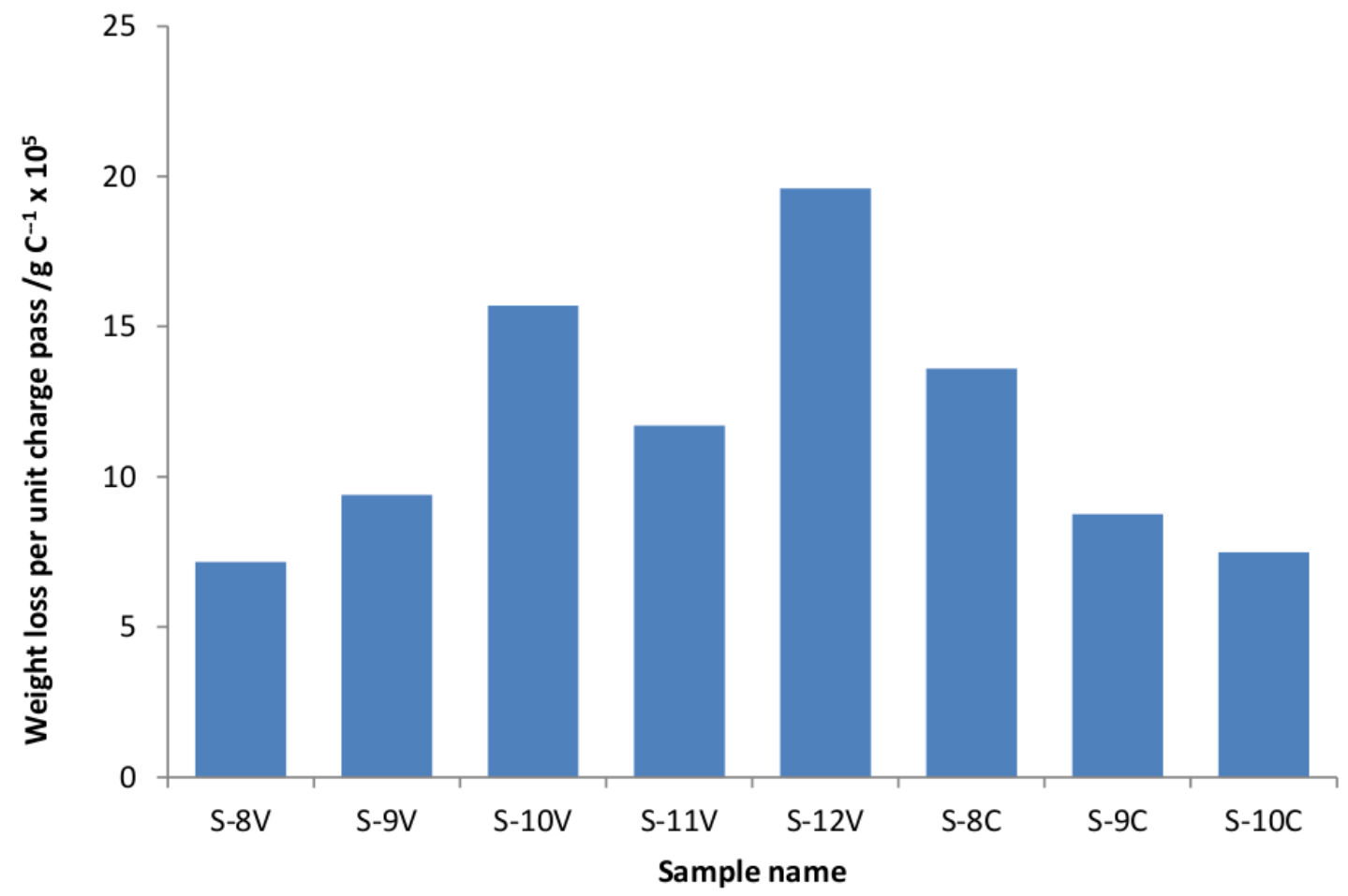

Figure 8:

Total mass loss from the sample during electropolishing as a function of Faradaic charge passed for a range of electropolished samples under constant current $(\mathrm{S}-x \mathrm{C})$ or constant applied potential $(\mathrm{S}-x \mathrm{~V})$ regimes. 


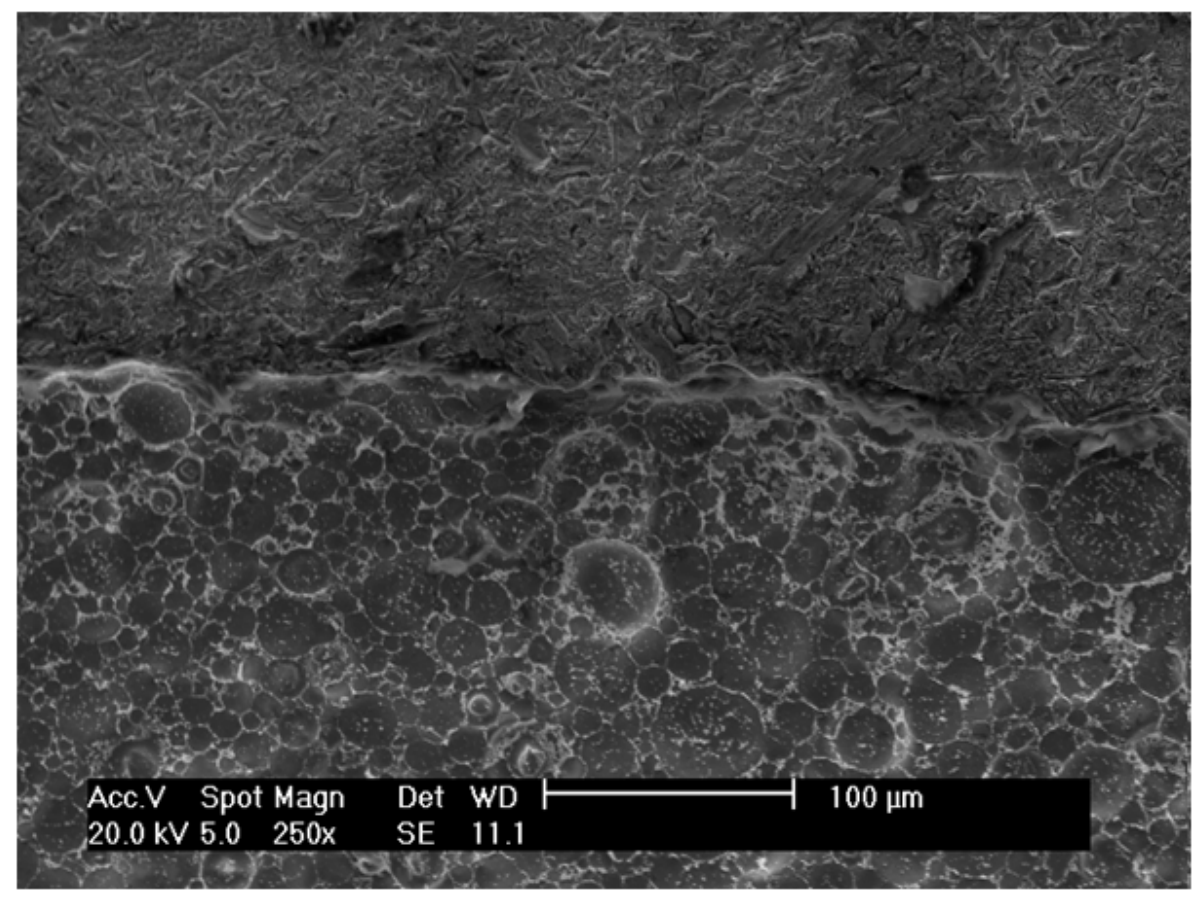

(a)

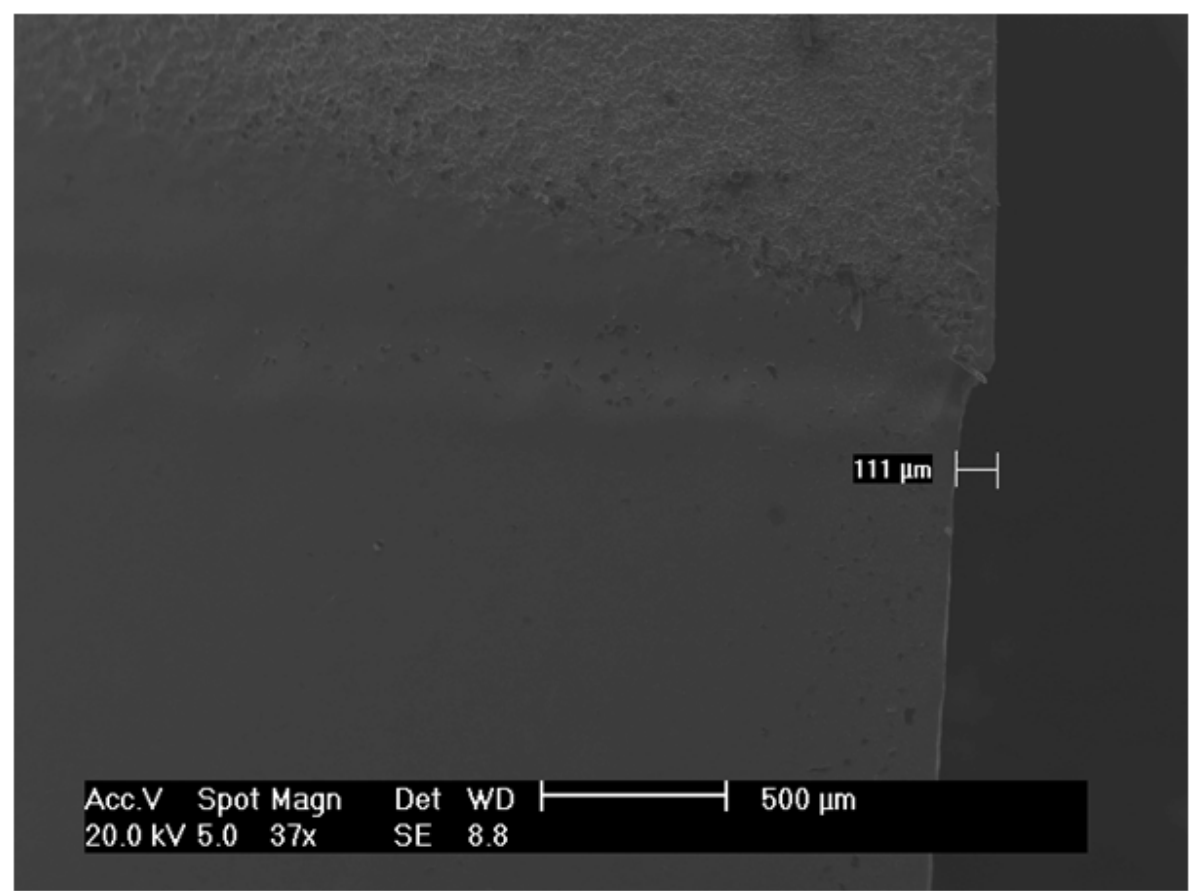

(b)

Figure 9: $\quad$ SEM images of sample S-9V electropolished for 120 minutes at $6 \mathrm{~V}$ in MSA/GA; (a) showing the boundary region between unpolished (top) and polished (bottom) surfaces; (b) SEM in profile showing the etch-step edge. 


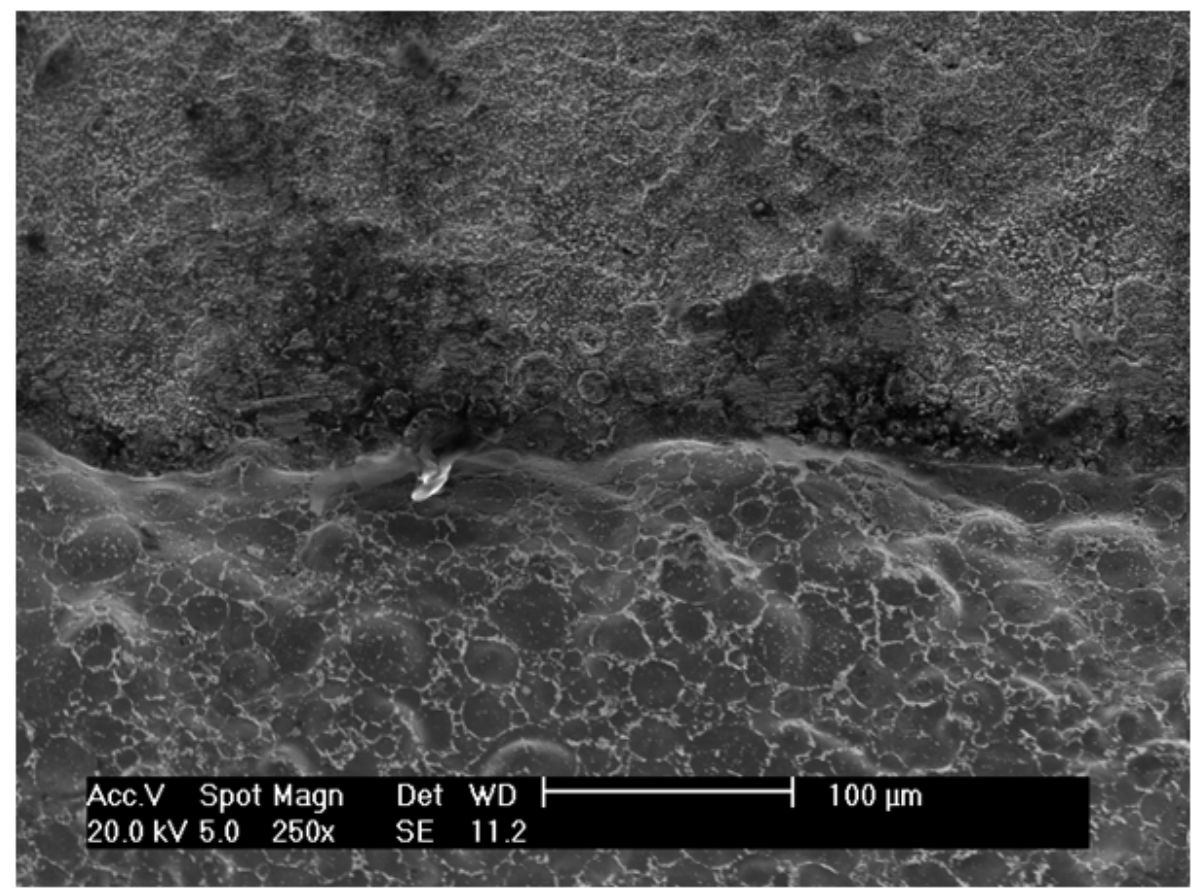

(a)

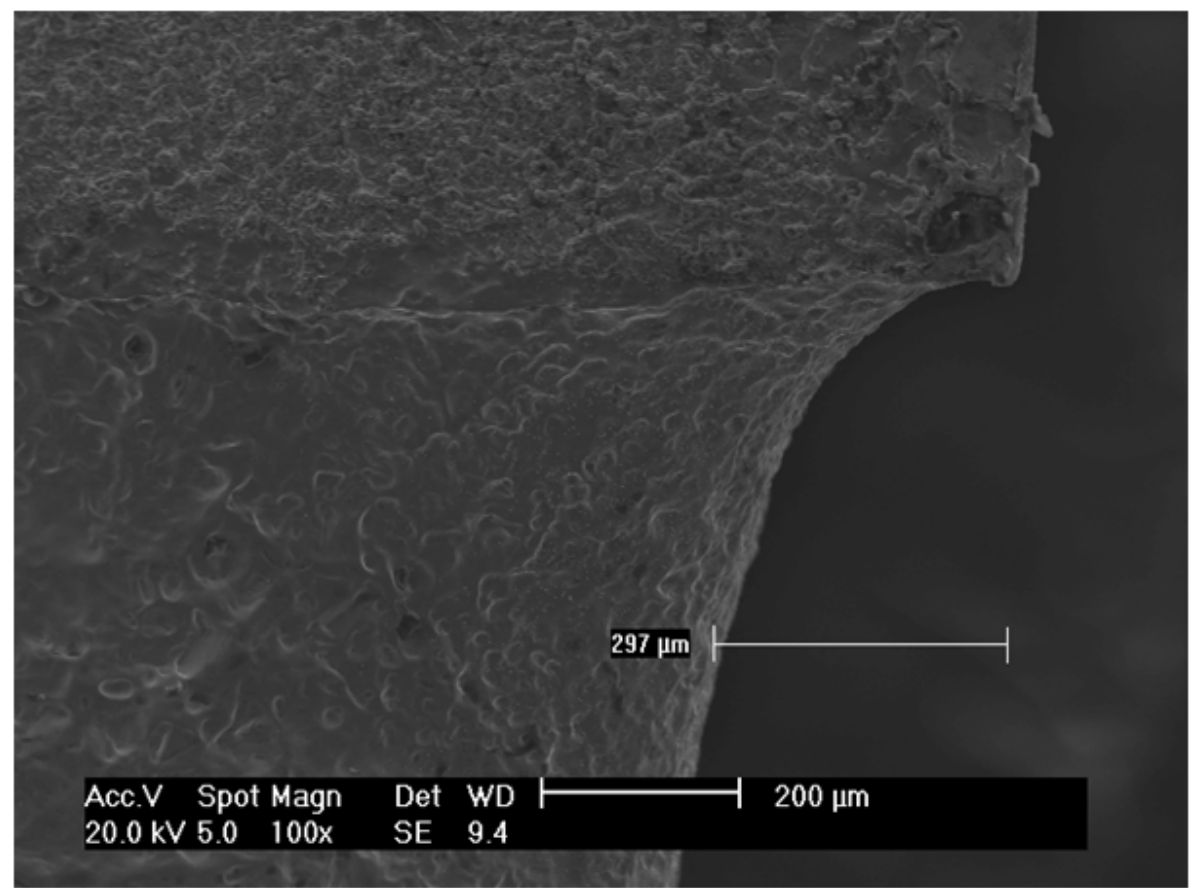

(b)

Figure 10: $\quad$ SEM images of sample S-11V electropolished for 120 minutes at $10 \mathrm{~V}$ in 2Eg: $\mathrm{ChCl} ;$ (a) image showing the boundary region between unpolished (top) and polished (bottom) surfaces; (b) SEM in profile showing the etch-step edge. 


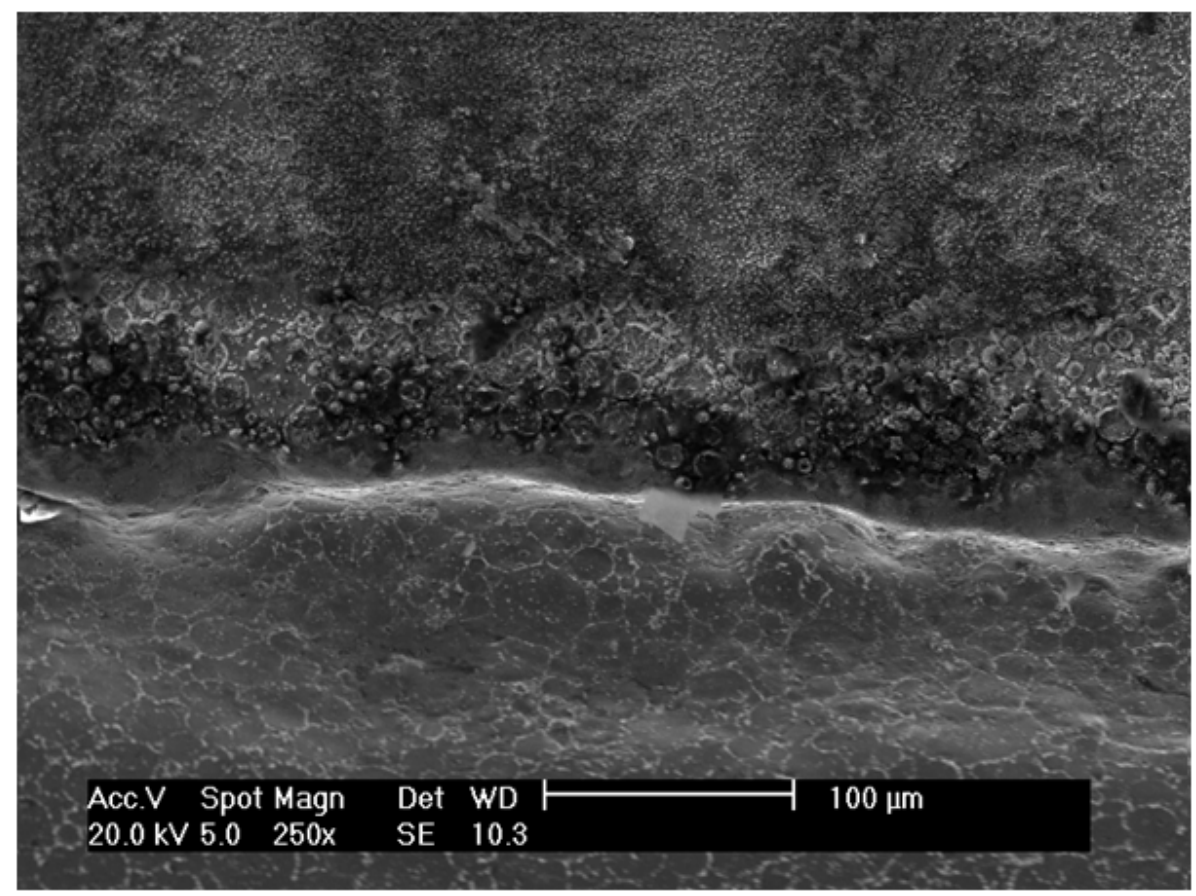

(a)

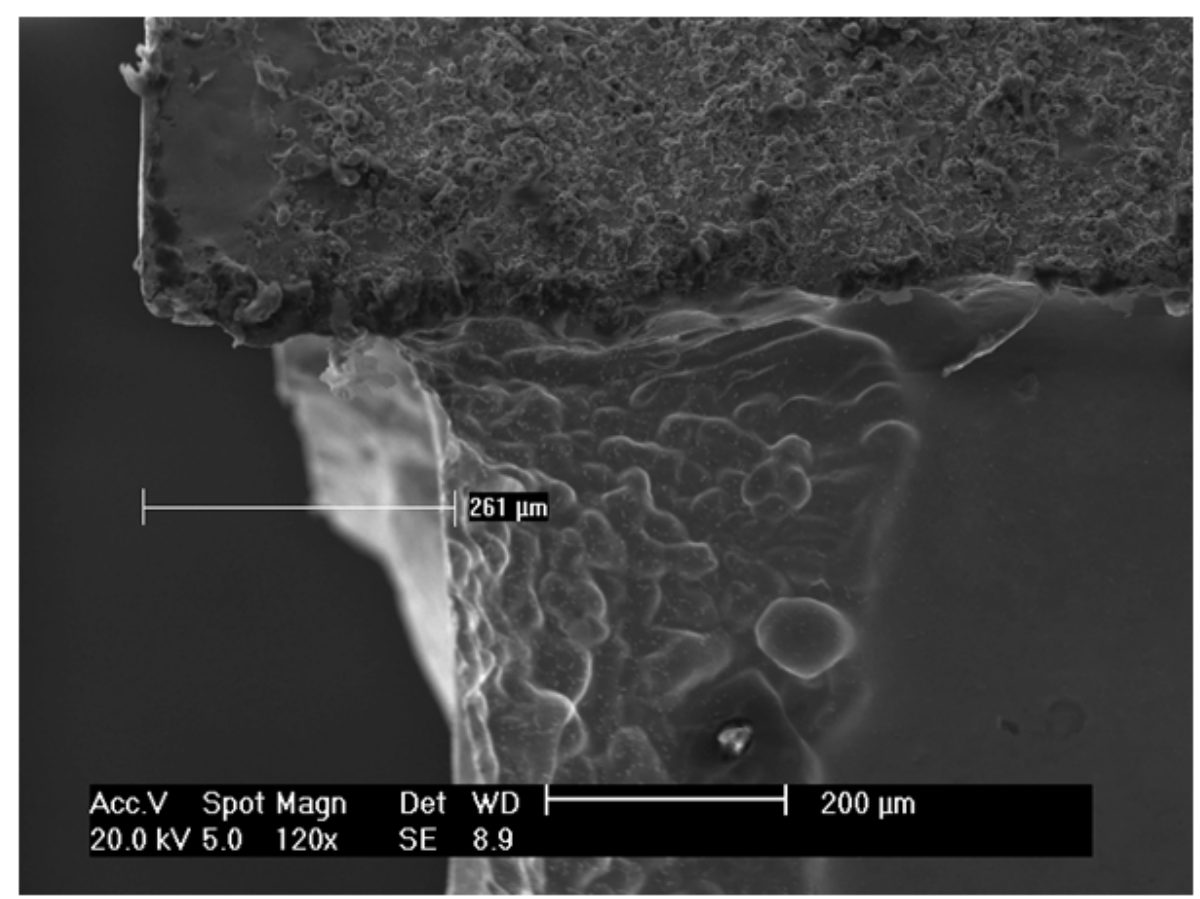

(b)

Figure 11: $\quad$ SEM images of sample S-12V electropolished for 120 minutes at $10 \mathrm{~V}$ in mixed electrolyte comprising [90\% 2Eg: $\mathrm{ChCl}: 10 \% \mathrm{MSA} / \mathrm{GA}]$; (a) image showing the boundary region between unpolished (top) and polished (bottom) surfaces; (b) SEM in profile showing the etch-step edge. 


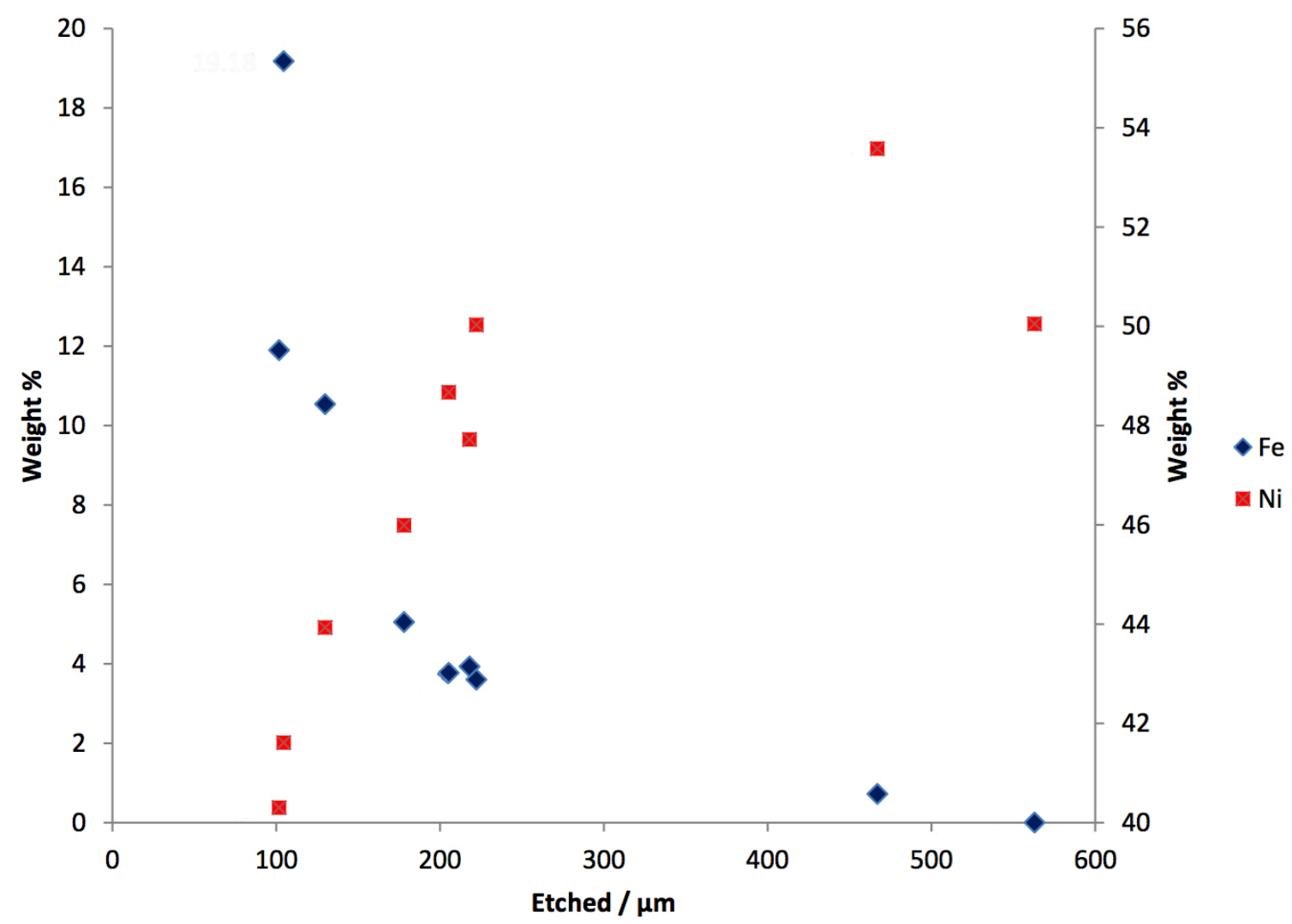

Figure 12: $\quad$ EDX analysis of electropolished surface for Fe (blue diamonds), left axis, and $\mathrm{Ni}$ (red squares), right axis, as a function of etched depth for all samples electropolished under constant current and constant potential. 


\section{References}

1 “The Superalloys: Fundamentals and Applications”, R. C. Reed, Cambridge University Press, Cambridge, 2006.

2 "Solidification Characteristics and Segregation Behavior of Nickel-Base Superalloys in Dependence on Different Rhenium and Ruthenium Contents", A. Heckl, R. Rettig, R.F. Singer, Metal. Mater. Trans. A, 2010, 41A, 202-211.

3 "Elemental partitioning of platinum group metal containing Ni-base superalloys using electron microprobe analysis and atom probe tomography", J.S. Van Sluytman, A. La Fontaine, J.M. Cairney, Acta Materialia, 2010, 58, 1952-1962.

4 "The Effect of Secondary Gamma-Prime on the Primary Creep Behavior of Single-Crystal Nickel-Base Superalloys", B.C. Wilson, G.E. Fuchs, Metall. Mater. Trans. A, 2010, 41A, 1235-1245.

5 "Quenching Differential Thermal Analysis and Thermodynamic Calculation to Determine Partition Coefficients of Solute Elements in Simplified Ni-Base Superalloys", J. Valdes, S.L. Shang, Z.K. Liu, P. King, X.B. Liu, Metall. Mater. Trans. A, 2010, 41A, 487-498.

6 "Effect of Ruthenium on Creep Strength of Ni-Base Single-Crystal Superalloys at $750{ }^{\circ} \mathrm{C}$ and $750 \mathrm{MPa}$ ", N. Tsuno, K. Kakehi, C.M.F. Rae, R. Hashizume, Metall. Mater. Trans. A, 2009, 40A, 269-272.

7 "Structural Stability of Platinum-Group-Metal-Modified gamma plus gamma' Ni-Base Alloys", A.J. Heidoloff, J. Van Sluytman, T.M. Pollock, B. Gleeson, Metall. Mater. Trans. A, 2009, 40A, 1529-1540

8 "Accuracy of composition measurement using $X$-ray spectroscopy in precipitate-strengthened alloys: Application to Ni-base superalloys", N. D’Souza, R. Beanland, C. Hayward, H.B. Dong, Acta Materialia, 2011, 59, 1003-1013.

9 "High-Temperature Creep Deformation and Fracture Behavior of a Directionally Solidified Ni-Base Superalloy DZ951", Z.K. Chu, J.J. Yu, X.F. Sun, H.R. Guan, Z.Q. Hu, Metall. Mater. Trans. A, 2009, 40A, 2927-2937.

10 "Powder Metallurgy Methods and Applications", W.B. James, Powder Metallurgy Vol. 7, ASM Handbook, Ed. P. Samal and J. Newkirk, ASM International, 2015, 11-19.

11 “An overview of Hot Isostatic Pressing”, N.L. Loh and K.Y. Sia, J. Mater. Process. Tech., 1992, 30, 4556.

12 "Hot Isostatic Pressing (HIP) technology and its applications to metals and ceramics", M. H. Bocanegra-Bernal, J. Mater. Sci., 2004, 39, 6399-6420.

13 “Anodic dissolution mechanisms of metals and alloys", T. Tsuru, Materials Sci. and Eng., 1991, A146, 114.

14 "Electropolishing of 304 stainless steel: Surface roughness control using experimental design strategies and a summarized electropolishing model", C.-C. Lin, C.-C. Hu, Electrochem. Acta, 2008, 53, 33563363.

15 "Electropolishing of 304 stainless steel: Interactive effects of glycerol content, bath temperature, and current density on surface roughness and morphology", C.-C. Lin, C.-C. Hu, T.-C. Lee, Surf. \& Coatings Technol., 2009, 204, 448-454.

16 "Electropolishing process for Co and Co Alloys", Siegfried Piesslinger-chweiger, US Patent No. US8,080,148 B2, Dec. 2011.

17 "Electrofinishing of Metals using Eutectic Based Ionic Liquids", A.P. Abbott, K.S. Ryder and U. Koenig, Trans. IMF, 2008, 86, 196-204.

18 "Electrolytic Metal Coatings and Metal Finishing Using Ionic Liquids", A.P. Abbott, J.C. Barron, M.Elhadi, G. Frisch, S.J. Gurman, A.R. Hillman, E.L. Smith, M.A. Mohamoud and K.S. Ryder, ECS Trans., 2009, 16 (36), 47-63.

19 "Electropolishing of Stainless Steels in a Choline Chloride Based Ionic Liquid: An Electrochemical Study With Surface Characterisation Using SEM and Atomic Force Microscopy", A.P. Abbott, G. Capper, K.J. McKenzie, A. Glidle and K.S. Ryder, Phys. Chem. Chem. Phys., 2006, 8, 4214-4221.

20 "Voltammetric and Impedance Studies of the Electropolishing of 316 Stainless Steel in Choline Chloride/ Ethylene Glycol Mixtures", A.P. Abbott, G. Capper, K.J. McKenzie and K.S. Ryder, Electrochimica Acta, 2006, 51, 4420-4425. 
21 "Metal Finishing with Ionic Liquids; Scale-up \& Pilot Plants from the IONMET Consortium", E.L. Smith, C. Fullarton, R.C. Harris, S. Saleem, A.P. Abbott and K.S. Ryder, Trans. IMF, 2010, 88(6), 285291.

22 "Ionic Liquids: industrial applications for green chemistry", ACS symposium series; 818, 2002 , ed. Robin D. Rogers and Ken R. Seddon.

23 "Electrodeposition in Ionic Liquids", Edited by F. Endres,A.P. Abbott and D.R. Macfarlane, Wiley-VCH Weinheim, 2008, ISBN: 978-3-527-31565-9

24 "Deep Eutectic Solvents (DESs) and their Applications", Emma L. Smith, Karl S. Ryder and Andrew P. Abbott, Chem. Rev., 2014, 114, 11060-11082.

25 "Electrolytic Processing of Super-alloy Aerospace Castingsusing Cholinechloride-based Ionic Liquids", A.P. Abbott, N. Dsouza, P. Withey and K.S. Ryder, Trans. IMF, 2012, 90(1), 9-14.

26 "Microstructure and Mechanical Properties of an Advanced Nickel-Based Superalloy in the as-HIP Form", J.R. May, M.C. Hardy, M.R. Bache, and D. D. Kaylor, Euro Superalloys 2010, M. Heilmaier (Ed.), Advanced Materials Research, 2011, 278, 265-270.

27 "Influence of Hot Isostatic Pressing temperature on microstructure and tensile properties of a nickelbased superalloy powder", C.L. Qiu, M.M. Attallah, X.H. Wu and P. Andrews, Materials Science \& Engineering, 2013, A564, 176-185.

28 "Removal of casting defects from CMSX-4 and CMSX-10 alloys by electropolishing in a novel electrolyte; Deep Eutectic Solvent", Neil Dsouza, Matthew Appleton, Andrew Ballantyne, Amy Cook, Robert Harris and Karl S. Ryder, Eurosuperalloys 2014, MATEC Web of Conferences, 2014, 14, 13007, $1-7$.

29 "Compositional variations for small-scale gamma prime $(\gamma$ ') precipitates formed at different cooling rates in an advanced Ni-based superalloy”, Y.Q. Chen, E. Francis, J. Robson, M. Preuss and S.J. Haigh, Acta Materialia, 2015, 85 199-206. 